Haro P, Villanueva Perales AL, Arjona R, Ollero P. Thermochemical biorefineries with multiproduction using a platform chemical. Biofuel Bioprod Biorefining 2014;8(2):155-170. DOI: 10.1002/bbb.1409

\title{
Thermochemical Biorefineries with multiproduction using a platform chemical
}

\author{
Pedro Haro ${ }^{a,{ }^{*}}$, Ángel Luis Villanueva Perales ${ }^{a}$, Ricardo Arjona ${ }^{b}$, Pedro Ollero ${ }^{a}$ \\ a Bioenergy Group, Chemical and Environmental Engineering Department. Escuela Superior de \\ Ingenieros, Universidad de Sevilla. Camino de los Descubrimientos s/n. 41092 Seville, Spain \\ ${ }^{b}$ Abengoa Bioenergy New Technologies (ABNT), Spain \\ * corresponding author: e-mail address: pedrogh@us.es; Tel.: +34 95 4487265; Fax: +34 954461775
}

\begin{abstract}
Multiproduction is a promising option for thermochemical biorefineries in order to reduce the risk of investment. It promotes the diversification of revenue, allows a better material and energy integration and enhances profitability, which could improve the future development of thermochemical biorefineries. However, the design of thermochemical biorefineries with multiproduction requires of new tools and new perspectives that differ from those that have been used in the design of biomass-to-liquid/gas (BTL/G) processes, which are single product orientated. The use of a platform chemical has revealed a new field of promising possibilities for multiproduction. Nonetheless, the consideration of several kinds of final products makes difficult the calculation of the energy efficiency and the assessment of both sustainability and profitability. In case of sustainability, it is necessary to know how to allocate the GHG emissions of each product (including electricity) and the potential impact of the production of chemicals, which are not combusted in their final use and bring a net retention of carbon. The incorporation of Bioenergy with Carbon Capture and Storage (BECCS) is assessed as a potential income for this kind of biorefinery, which could also achieve a larger saving of GHG emissions than that regulated by European administration. The design of thermochemical biorefineries with multiproduction, in case of using a platform chemical, are able to co-produce low-value highvolume products like fuels along with high-value low-volume products like solvents and chemicals, which have been demonstrated by conventional oil refineries to be highly profitable.
\end{abstract}

Keywords: thermochemical biorefinery, platform chemical, process design, sustainability

\section{Introduction}

Biomass as a substitute of fossil feedstock for the production of transportation fuels, chemicals and materials is of great interest nowadays. Biomass is converted into products via biochemical processing (a combination of mechanical, chemical and biological technologies) and/or thermochemical processing (using pyrolysis and/or gasification technologies). The term biorefinery has been widely accepted as referring to plants processing biomass. ${ }^{1-9}$ In the case of 
plants using biochemical processing, we talk about biochemical biorefineries, whereas plants using thermochemical processing would be thermochemical biorefineries. The classification of biorefineries regarding their processing could be problematic in the case of plants using both biochemical and thermochemical technologies.

The biochemical biorefineries are currently commercial (production of $1^{\text {st }}$ generation bioethanol) since they are simple and relatively cheap plants that operate at mild conditions of pressure and temperature and due to the availability of equipment, which requires a relatively low investment. However, in thermochemical biorefineries, the operating conditions are severe for gasification, pyrolysis and synthesis, which involve a large investment cost. Hence, thermochemical biorefineries require a larger scale in order to be profitable. The required equipment for thermal processing (pyrolysis and gasification) is still not commercial. ${ }^{*}$ Furthermore, there are also difficulties for the cleaning and conditioning of syngas that could increase the investment cost, making the process hardly profitable. These disadvantages of thermochemical biorefineries have slowed their development along with the uncertainties in the bioenergy sector (regulation) and the volatility of the price of fossil fuels (mainly crude oil and natural gas).

In this paper, we aim to describe thermochemical biorefineries based on biomass gasification focused on multiproduction (co-production of fuels, chemicals and services), especially in the case of using a platform chemical. A platform chemical is considered, in this paper, ${ }^{\dagger}$ as an intermediate compound, which is further converted into a new platform chemical or into final products. ${ }^{10}$ Thermochemical biorefineries using a platform chemical are capable of producing the same products as current refineries using crude oil (not only transportation fuels, but also commodities for the chemical industry), so their products could be directly sold in current energy and chemical markets. In addition, multiproduction raises some difficulties in the assessment of sustainability and economics that requires further study.

\section{Fundamentals of thermochemical biorefineries}

A thermochemical biorefinery is a facility, which processes biomass by means of pyrolysis and/or gasification to produce fuels (transportation, heat/electricity generation), chemicals (highvalue, commodities), materials and services (heat, electricity). In a thermochemical biorefinery, the production can be focused either on a single product, for example Fisher-Tropsch (FT) diesel, or on a mix of products (multiproduction). In a thermochemical biorefinery, biomass (syngas or bio-oil) is processed like in a petrochemical facility. For instance, the technologies and know-how from the petrochemical industry apply to the design of thermochemical biorefineries. The conversion of syngas into transportation fuels (FT-diesel, synthetic gasoline) and commodities like methanol are well-known technologies using natural gas or coal (carbochemistry) as a feedstock.

\footnotetext{
* However, it is commercial in case of using coal as feedstock. The Sasol process, a coal-to-liquid (CTL) process, is the example of the co-production of different products at large scale in the same way as conventional refineries. $\dagger$ This definition is different to that of the IEA (International Energy Agency) used for the classification of biorefineries using four features. ${ }^{2}$
} 


\subsection{Thermochemical biorefineries focused on a single product: direct and indirect}

\section{synthesis}

Thermochemical biorefineries that use a direct route (syngas-to-product) for the production of a single product are known as BTL/G (biomass-to-liquid/gas) plants. In this kind of plant, the processing sections are usually easily distinguishable (see Figure 1). The design of a BTL/G plant usually suffers from a limitation of process integration and profitability, due to the maximization of the single production (e.g. larger recirculation, larger equipment, higher cost; and lower energy efficiency). The selectivity to the desired product is frequently poor in case of liquid biofuels and a large amount of subproducts (or undesired by-products) is generated in the plant. Furthermore, the operating pressure is high (e.g. 80 bar) and syngas cleaning requirements are severe.

An alternative to direct synthesis from syngas is the conversion of syngas using a platform chemical, i.e. indirect synthesis. The benefits of indirect synthesis are the overcoming of some of the technical and operational difficulties of direct synthesis, and that both net investment and operating cost are similar to in case of direct synthesis. For example, in this kind of plant, the recycling of unconverted syngas is reduced or there is not such a recycle. Since there are several (in-series) reaction steps, the syngas is fractionally converted in each reactor step and a large global conversion of the syngas is achieved without recycling. Furthermore, the milder operating pressure and optimum conversion of the syngas (in terms of required molar $\mathrm{H}_{2} / \mathrm{CO}$ ratio) balances the inclusion of extra equipment (several reactors). An example of the benefits of this kind of plant is presented in our previous work for the indirect synthesis of ethanol using dimethyl ether (DME). ${ }^{10}$ The design of these biorefineries has a greater complexity and the processing sections of the plant become difficult to distinguish (see Figure 2). The use of a platform chemical involves several reaction steps, i.e. conversion of the biomass-derived syngas into the platform chemical (in 1 or 2 steps, e.g. DME synthesis), conversion of the platform chemical into the desired product, and recycle/conversion of by-products (they could be recycled to an existing reactor or converted in an on purpose reactor). Furthermore, the product separation section is larger and the process integration (material and energy) becomes crucial.

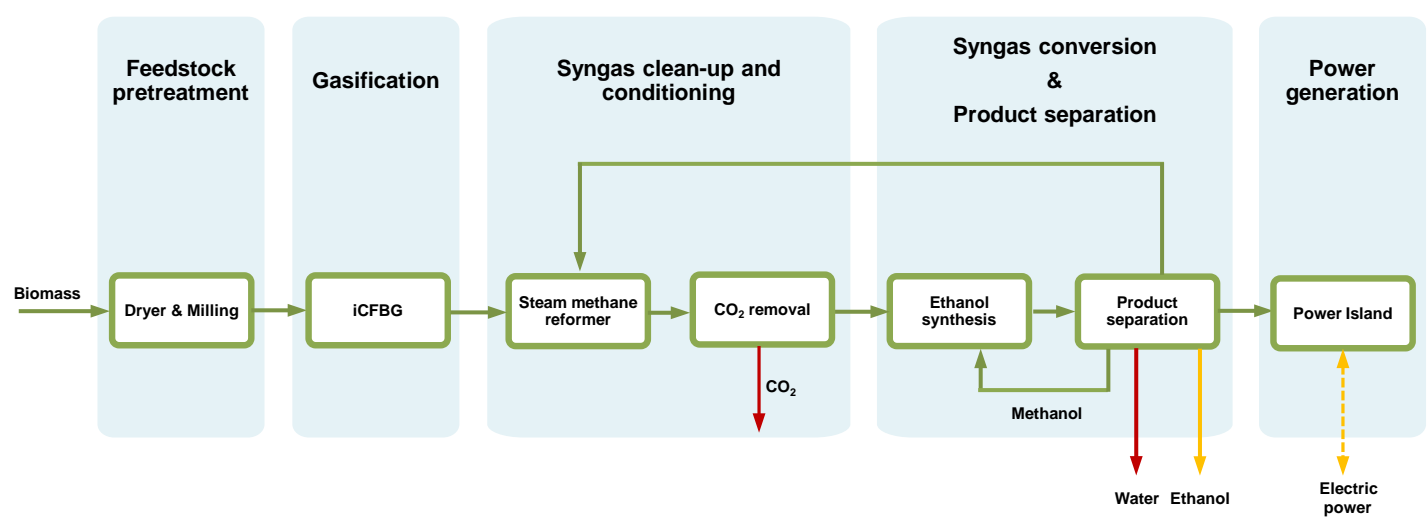


Figure 1. Scheme of a BTL/G plant (thermochemical biorefinery focused on a single product directly from syngas).

Case: direct synthesis of ethanol. iCFB: indirect Circulating Fluidized Bed Gasifier.

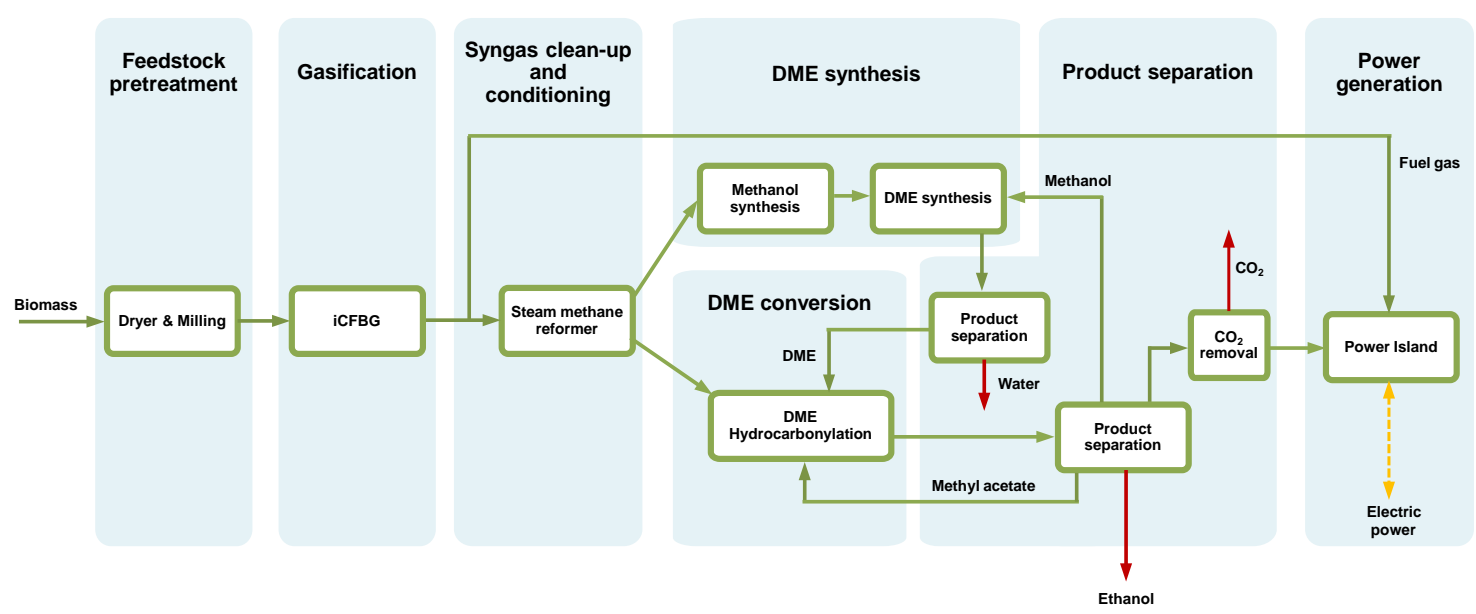

Figure 2. Scheme of a thermochemical biorefinery focused on a single product indirectly from syngas (using a platform chemical). Case: indirect synthesis of ethanol. ${ }^{11}$ iCFB: indirect Circulating Fluidized Bed Gasifier.

\subsection{Thermochemical biorefineries focused on multiproduction: with and without the use}

\section{of a platform chemical}

The co-production of transportation fuels, other fuels (e.g. for heating), commodities and services (electricity and heat) creates important benefits that could be applied to thermochemical biorefineries. In a conventional (crude oil) refinery there are sorts of products which are diverted into different sectors: transport (gasoline, diesel, kerosene), petrochemical industry (olefins, $\mathrm{BT} \mathrm{X}^{\ddagger}$ ), and energy ( $\mathrm{LPG}^{\S}$, fuel oil, electricity). Therefore, a refinery does not depend on a single market. In addition, as the refinery combines different processes, it can be well integrated energetically and materially, since all byproducts and off-gas streams are efficiently used in order to maximize the global production, i.e. enhancing energy efficiency. The benefits of co-production (multiproduction) are also applicable to thermochemical biorefineries. In this paper, multiproduction is considered as the simultaneous co-production of products and services.

Multiproduction in thermochemical biorefineries could be achieved by two different approaches. One option is the combination of different direct routes (the syngas is split into different reaction steps), which would be the combination of several BTL/G processes (syngas-to-product). However, this option does not allow good integration of the synthesis areas, since, for example, the production of byproducts is not avoided. Another option is the combination of different chemical routes sharing a platform chemical (the syngas is converted into a platform chemical, which is further diverted into several reaction steps). The use of a platform chemical, such as a common intermediate, allows better material and energy integration in the plant. ${ }^{12}$ Moreover, the platform chemical could be a product itself, i.e. not fully converted into final products. The

‡ Benzene, Toluene and Xylenes.

$\S$ Liquefied Petroleum Gases. 
generation of byproducts is avoided if several routes sharing the same platform chemical are used (the byproducts are diverted to other synthesis reactors, see Figure 3). In a thermochemical biorefinery with multiproduction, the use of a platform chemical gives a layout similar to that in BTL/G plants, avoiding the recycling of unconverted syngas (see Figure 4).
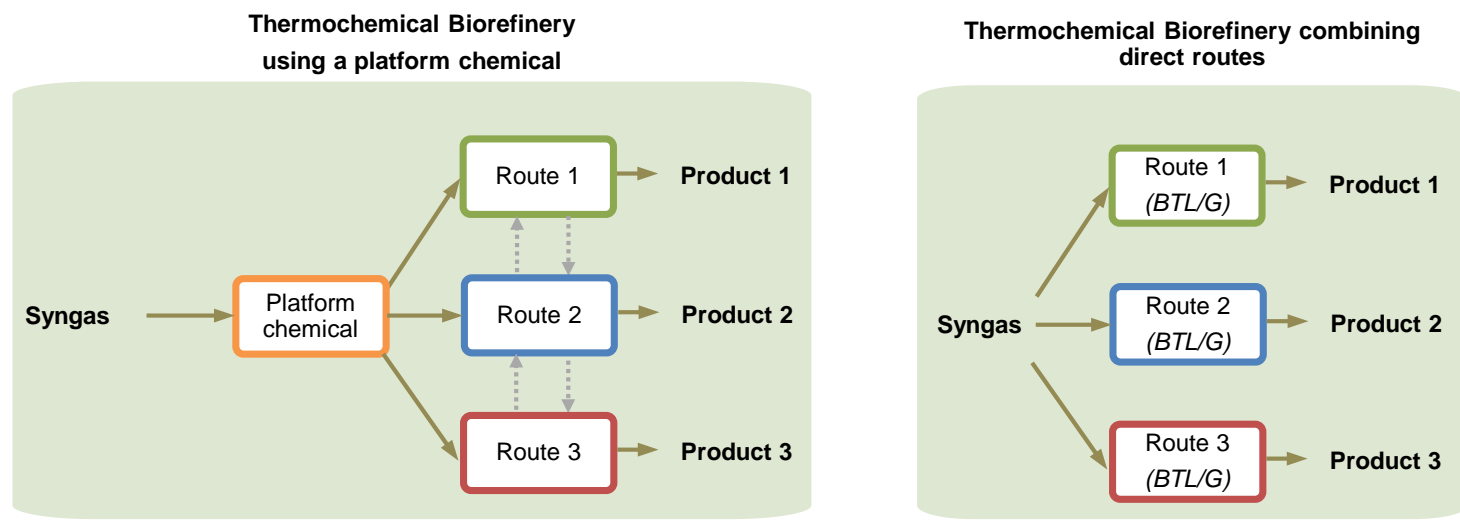

Figure 3. Different schemes for multiproduction using a platform chemical or by the combination of different direct routes from syngas.

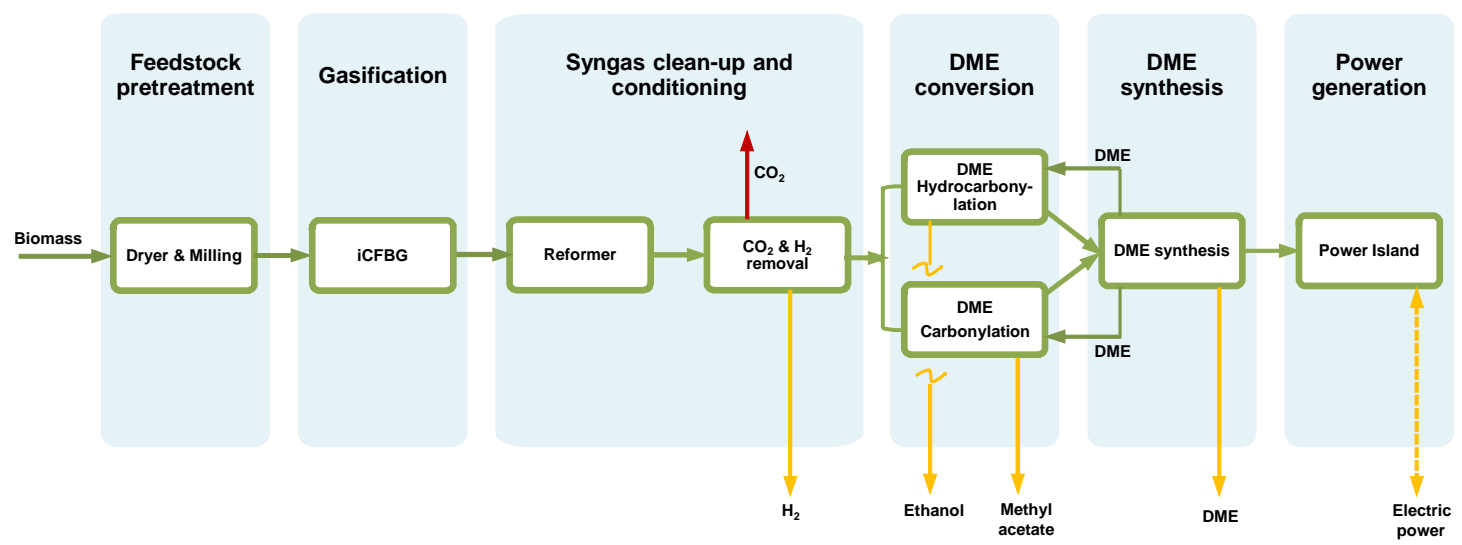

Figure 4. Scheme of a thermochemical biorefinery with multiproduction using a platform chemical. Case: DME (hydro)carbonylation route. iCFB: indirect Circulating Fluidized Bed Gasifier.

\subsection{Previous research on thermochemical biorefineries with multiproduction}

Up to now, efforts in thermochemical biorefineries have usually been limited to BTL/G processes (single product, using a direct route). The term thermochemical biorefinery is currently scarce in the literature of the thermochemical processing of biomass. ${ }^{2,4,13-17}$ Some previous assessments of thermochemical biorefineries with multiproduction using a platform chemical are given by Zwart and other authors. ${ }^{12,17-20}$ The design of thermochemical biorefineries using biomass-derived bio-oil is also scarce. ${ }^{22}$ Regarding other kinds of biorefineries with multiproduction, examples of two-platform biorefineries (combining biochemical and thermochemical processing) are given elsewhere. ${ }^{6,15,23,24}$ Other studies focused on the co-feeding of fossil fuels and multiproduction combining direct routes are given by Baliban and other authors. ${ }^{25-29}$ 


\section{Thermochemical Biorefineries with multiproduction using a platform chemical}

The benefits of thermochemical biorefineries with multiproduction using a platform chemical are:

- Better energy and material integration.

- The overcoming of some of the technical and operational difficulties of BTL/G processes (direct synthesis) for the production of liquid biofuels.

- Milder operating conditions, which balances the increase in plant size (larger synthesis and product separation areas), resulting in similar investment and operating cost as in BTL/G processes.

- The diversification of revenues, which reduces the uncertainty of the market price of bio-products.

However, this kind of biorefinery is harder to design and assess than BTL/G processes. Multiproduction involves several alternatives for the calculation of energy efficiency. The selection of the mix of products and their relative production rely on the platform chemical and the availability of chemical platform-to-products routes. For the economic assessment, the calculation of the minimum selling price by fixing the internal rate of return is not possible now (typical in BTL/G assessments). Alternatively, the selling price of co-products could be fixed to their current commercial value.

\subsection{Energy efficiency}

In a biorefinery, there are several kinds of energy qualities (products: fuels, chemicals; services: heat, electricity; and feedstock: biomass, heat, electricity). For example, the energy quality of biomass is not the same as that of electricity. The Chalmers University of Technology in its recent eBook "System perspective on Biorefineries" stated, "It is difficult to define a standard expression for evaluating efficiencies for biomass conversion processes, especially for biorefineries producing several products and energy services". ${ }^{9}$ This reference gives a perfect background of what this section deals with.

First, we discuss the energy qualities of the different inputs and outputs of a thermochemical biorefinery. The energy content of biomass, transportation fuels, chemicals and materials can be based on the low heating value (LHV) or the high heating value (HHV). There is some disagreement on the utilization of these energy bases in the literature, although HHV is more common. In thermochemical biorefineries, the use of a $\mathrm{HHV}$ basis is recommended. ${ }^{9}$ This assumption is not so clear for the case of chemicals and materials, which are not supposed to be burned, but processed in the petrochemical industry (chemicals) or directly used (solvents, materials). However, there is not a reasonable alternative for expressing the energy content in such products. 
If it is assumed that the different qualities of the products/services should be taken into account, the definition of a reference level is mandatory. The inputs to the biorefinery should be converted into their equivalent primary energy, which only in the case of the import of services (heat and/or electricity) requires the definition of conversion efficiency. ${ }^{9}$ The definition of the system boundaries is crucial in the calculation of the energy efficiency. The task should be carried out according to the layout of the biorefinery. For example, if in the design of the process an air separation unit (ASU) has been included e.g. to supply oxygen to an EF (entrained-flow) gasifier, the energy consumption of the ASU unit must be considered in the calculations of the efficiency. In the case of importing oxygen to the biorefinery, the equivalent primary energy should be taken into account. Of course, both cases do not have to give the same result for a given design of a thermochemical biorefinery.

Table 1 shows the different definitions of efficiency used in this paper, which are in agreement with those stated by Hamelinck. ${ }^{30,{ }^{* *}}$ For the conversion of electricity into primary energy, a global conversion efficiency $\left(\eta_{e}\right)$ is necessary. However, in the case of heat, despite there is a surplus, in most cases is of low quality (low temperature) and usually wasted. Regarding the special relevance of the studies considering it in the district heating, ${ }^{9,31}$ heat is included and a global conversion efficiency $\left(\eta_{h}\right)$ is used if necessary. The services in the biorefinery (electricity and heat) can be either an input or an output. However, they must not appear twice in the equation. For example, when calculating total efficiency, if the net electricity is an output to the biorefinery, it should be added to sum of products and not the biomass feedstock. It is also possible to use the expressions of Table 1 for the co-feeding of fossil fuels. For example, coal could be mixed with biomass for the gasification and/or natural gas reformed to produce more syngas in the plant (co-feeding) ${ }^{25,50,51}$ Of course, this extra input of energy should be accounted for in the efficiency.

Table 1. Energy efficiency in thermochemical biorefineries.

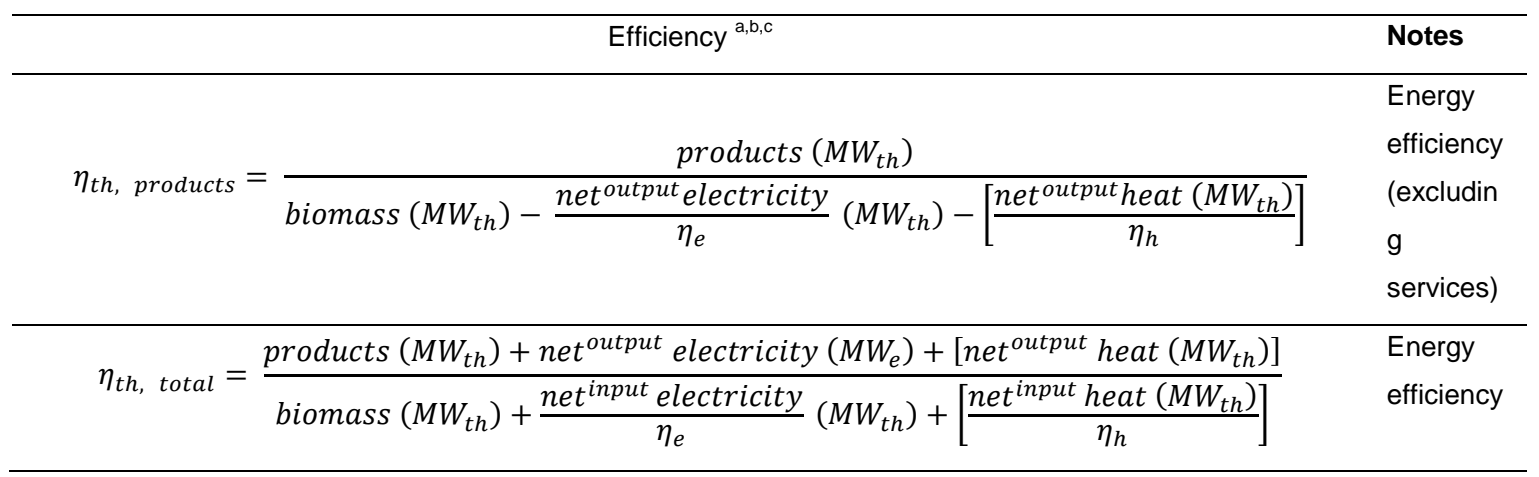

\footnotetext{
** In the literature, there are more examples of definitions of efficiency. Gassner et al. gives an efficiency to products different to that presented here (excluding electricity from the equation) and also in terms of exergy. Furthermore, the different qualities of energy are not taken into account and e.g. electricity is not converted into equivalent thermal content. $^{31}$
} 


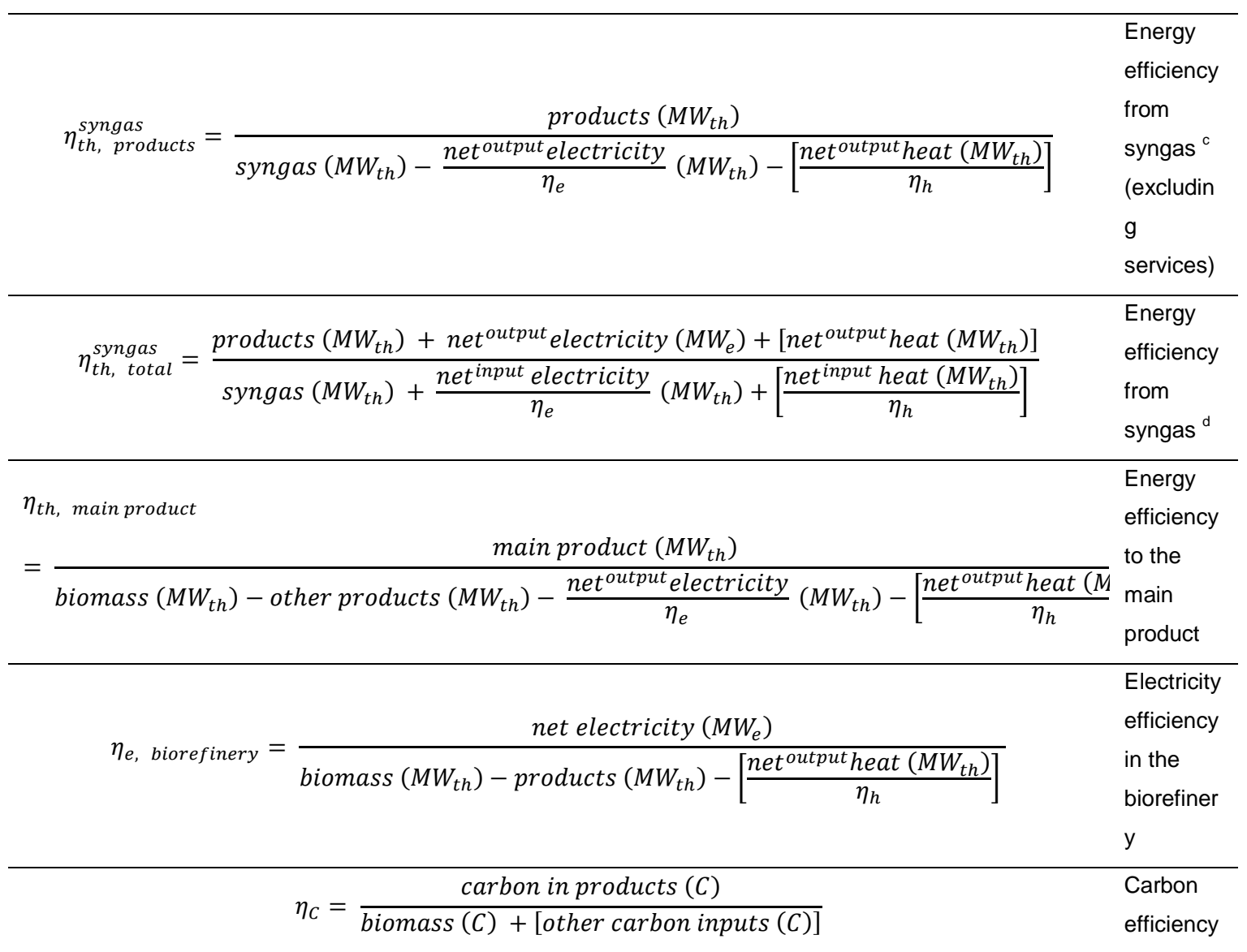

${ }^{a}$ The terms net ${ }^{\text {input }}$ (consumed - produced) and net ${ }^{\text {output }}$ (produced - consumed) are exclusive and only the one which is positive must appear in the equation as commented in the main text. When the only option is net ${ }^{\text {output }}$, it must appear regardless of the sign.

${ }^{\mathrm{b}}$ If there is a positive net heat, but it cannot be used (exported), then it should not be included in the expressions.

${ }^{\mathrm{c}}$ In the case of other inputs to the plant apart from biomass, e.g. co-feeding of fossil fuels, oxygen for direct gasification and/or autothermal reforming, the equivalent primary energy should be added to the denominator.

${ }^{d}$ In the case of the efficiency from syngas to products (and services), we consider the net electricity in the whole biorefinery, since in some configurations it is not possible to distinguish the fraction after the conditioning.

In order to explain the definitions of energy efficiency in Table 1, Figure 5 shows a comparison of them for a thermochemical biorefinery using DME as a platform chemical in 12 concepts of multiproduction (see Haro et al. for details) ${ }^{12}$. In the figure, the energy efficiency to all products and services $\left(\eta_{t h, \text { total }}\right)$, which is the most accurate definition in the case of multiproduction, is compared with the other definitions of energy efficiency in order to identify their weaknesses. Moreover, the possible export of heat is neglected. A first examination of the figure results in the fact that $\eta_{t h \text {, total }}$ and $\eta_{t h \text {, products }}$ are close (i.e. the points are close to the bisector -dashed line-) if the net electricity is small compared to the energy content of biomass feedstock. For the main product efficiency $\left(\eta_{t h \text {, main product }}\right)$ the values are lower than for $\eta_{t h \text {, total }}$ (i.e. below the bisector) and the difference grows with the grade of product diversification since only the main product is taken into account in $\eta_{t h \text {, main product }}$. For the efficiency from syngas to products $\left(\eta_{t h}^{\text {syngas }}\right.$, products $)$, there is a larger dependence on the electricity production/consumption in the biorefinery. In this case, the values do not lay around the bisector, but around a dotted line 
which represents the locus with constant biomass-to-syngas efficiency. Therefore, the different process concepts are compared without the influence of syngas production (a common step for all them). Finally, the carbon efficiency $\left(\eta_{C}\right)$ is useful to understand how the carbon in the biomass feedstock is transformed into products (containing carbon) and gives information about how the syngas is conditioned. However, it is a misleading indicator in the case of co-producing electricity or hydrogen. For example, the lowest values of carbon efficiency corresponds to process configurations using a tar reformer, which is the technology with highest $\mathrm{CO}_{2}$ production among those considered in the study (steam reformer, secondary reformer and tar reformer). The carbon efficiency depends on the mix of products, since in the case of coproducing ethanol, $\mathrm{H}_{2}$ and electricity, the carbon efficiency is poor (13\%), whereas the total efficiency is the greatest of the 12 concepts (51\%).

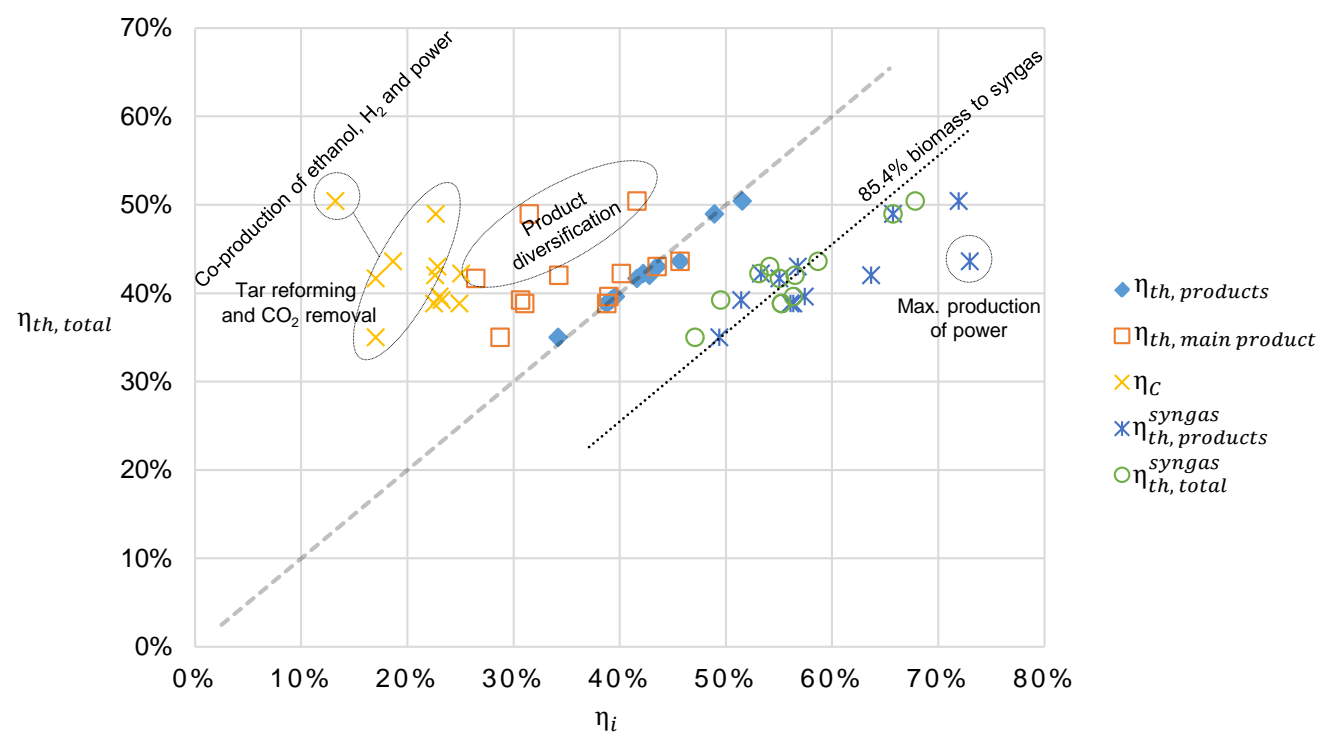

Figure 5. Efficiencies shown in Table 1 versus the total energy efficiency $\left(\eta_{t h, \text { total }}\right)$ for the concepts of thermochemical biorefinery with multiproduction presented in Haro et al., assuming a $\eta_{e}$ of $35 \%{ }^{12}$ The dashed line (bisector) represents the values of $\eta_{i}$ equal to $\eta_{t h \text {, total }}$. The dotted line represents the values of $\eta_{i}^{\text {syngas }}$ sharing the same biomass-to-syngas efficiency (same syngas production).

Figure 6 compares the energy efficiency of different concepts of thermochemical biorefineries with and without multiproduction. First, it is important to note that the selected cases were defined (in their corresponding references) as multiproduction only when a product apart from electricity was co-produced along with the main product. In terms of $\eta_{t h \text {, total }}^{\text {syngas }}$, the values of all cases are close (except for the co-production of ethanol and SNG where it is not available). Therefore, the inclusion of more reaction steps and a larger separation section for multiproduction does not mean lower energy efficiency. Looking at the co-production of gasoline and ethylene the resulting $\eta_{t h \text {, total }}$ is in between the case of producing gasoline and olefins separately (plants without multiproduction), whose reaction sections are combined for the multiproduction plant. Looking at the co-production of SNG and ethanol, the resulting $\eta_{t h \text {, total }}$ is 
much larger than the single production of ethanol (indirect synthesis) in a plant without multiproduction. This is because of the material integration between the ethanol synthesis and the methanation reactors (for further details see Reyes Valle et al. ${ }^{20}$. It is also remarkable the difference between the biomass-to-syngas efficiencies. Most cases have a biomass-to-syngas efficiency of $64.7 \%$ (dotted line), whereas the ethanol plant has a biomass-to-syngas efficiency of $76.6 \%$. These differences rely on how the biomass is pretreated (e.g. pyrolysis) and the syngas produced, cleaned and conditioned. Therefore, the conversion of the syngas for both (single product and multiproduction, in terms of $\eta_{t h \text {, total }}$ ) suffers of the biomass-to-syngas efficiency. Hence, as stated in Figure 5, the comparison of thermochemical biorefineries with and without multiproduction should be in terms of $\eta_{t h \text {, products. }}^{\text {syngas }}$ Figure 6 shows that comparing the values of $\eta_{t h \text {, products }}^{\text {syngas }}$, there is not a penalization for multiproduction in thermochemical biorefineries in terms of energy efficiency.

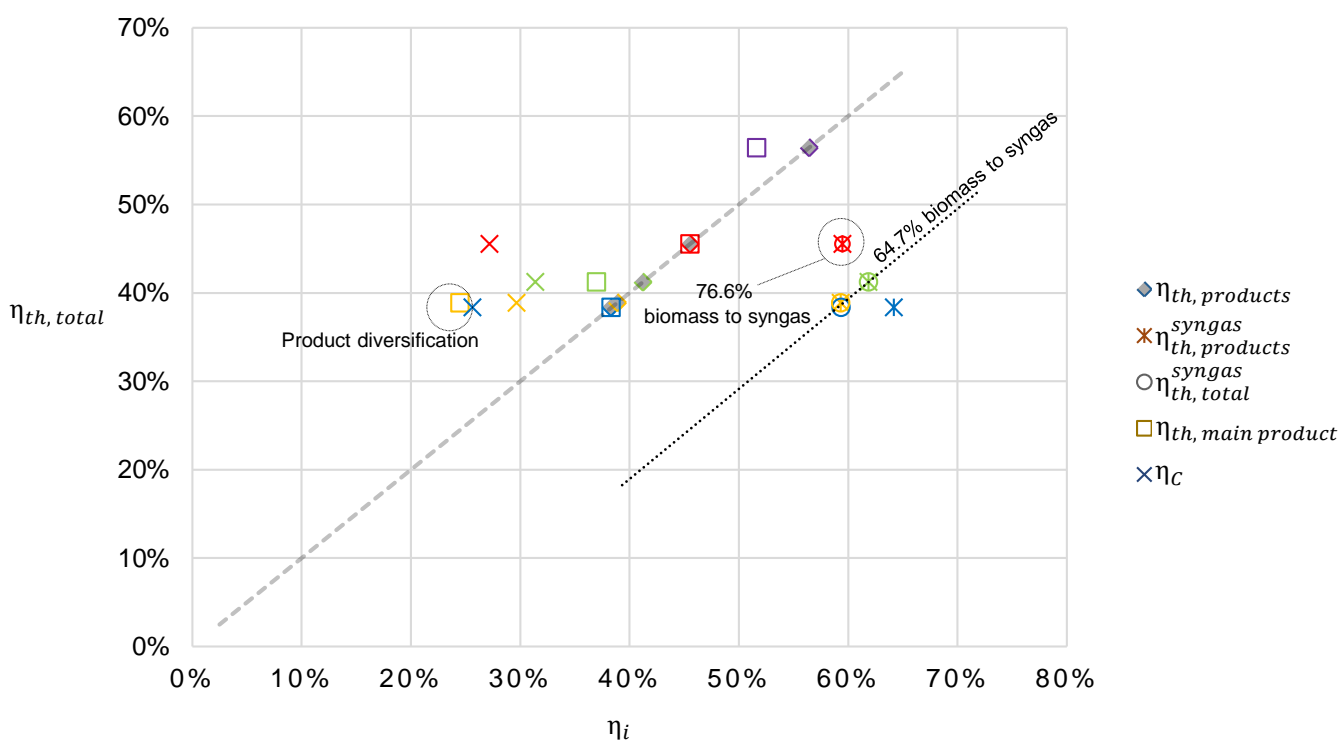

Figure 6. Comparison of energy efficiencies in thermochemical biorefinery with and without multiproduction, assuming a

\begin{tabular}{|c|c|}
\hline w multiproduction & w/o multiproduction \\
\hline Yellow: Co-production of gasoline \& ethylene $^{19}$ & Blue: Production of synthetic gasoline $^{19}$ \\
Purple: Co-production of SNG and ethanol $^{20}$ & Green: Production of olefins $^{19}$ \\
& Red: Production of ethanol via indirect synthesis $^{11}$ \\
\hline
\end{tabular}

The dashed line (bisector) represents the values of $\eta_{i}$ equal to $\eta_{t h \text {, total }}$. The dotted line represents the values of $\eta_{i}^{\text {syngas }}$ sharing the same biomass-to-syngas efficiency (same syngas production).

Regarding the definitions of efficiency in Table 1, the efficiency to electricity deserves further discussion. Sometimes, a neutral electric balance is imposed by producing the amount of electricity that is required in the plant. However, due to the medium to small production of electric power in the plant, the production of electricity should be carried out only using the purge and the excess heat of the plant, since the efficiency of a power plant would always be greater than the efficiency for the production of electricity in the biorefinery. Figure 7 shows the 
disaggregated efficiency to electricity of thermochemical biorefineries as a function of the net production of electricity. The efficiency to electricity in biorefineries is significantly lower.

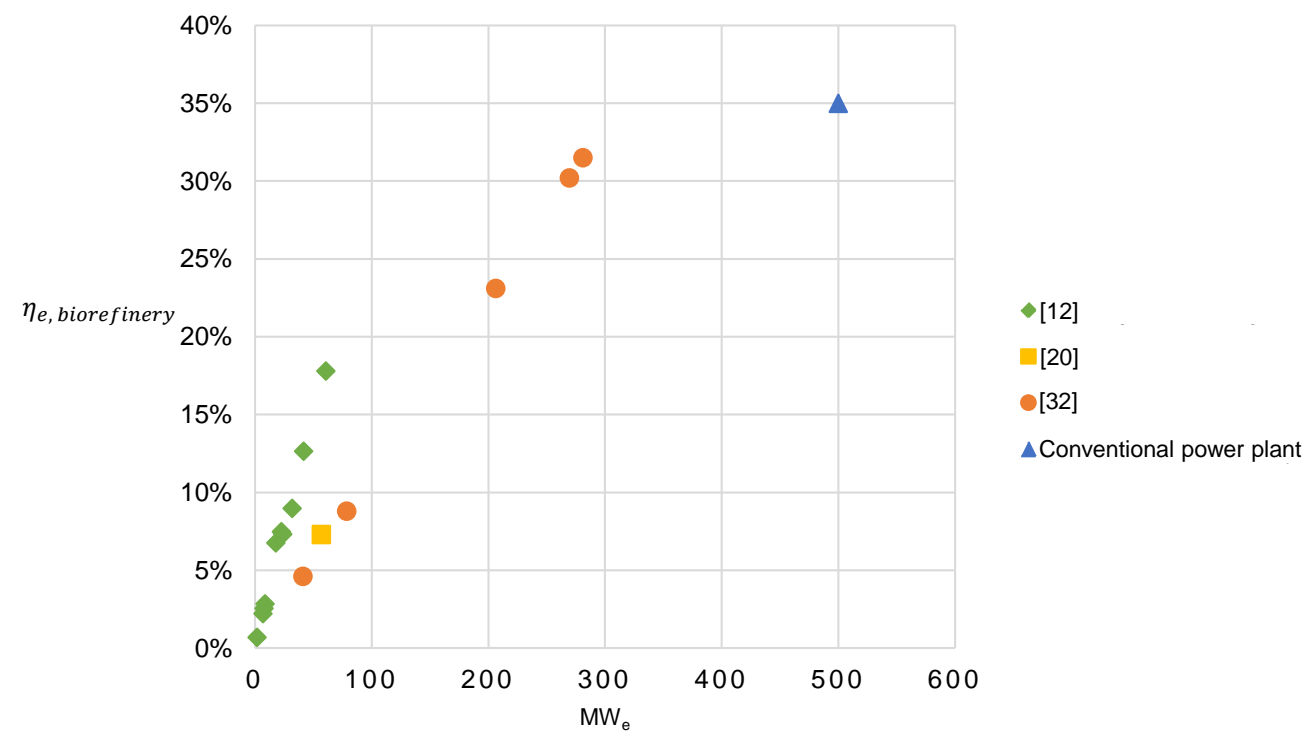

Figure 7. Efficiency to electricity for different references of thermochemical processing of biomass. ${ }^{12,20,32}$

\subsection{Environmental sustainability in thermochemical biorefineries}

It is interesting to discuss how GHG (greenhouse gas) can be assessed in thermochemical biorefineries. According to European regulations, sustainability is achieved when there is a saving of $35 \%$ of GHG emissions compared to current transportation fuels and fuels for heat and electricity generation (60\% from 2018). ${ }^{33}$ However, in a thermochemical biorefinery there are other products such as chemicals. The main failings and uncertainties in the assessment of environmental sustainability in thermochemical biorefineries are:

- In the methodology given by the EU, there is no reference (emissions of the fossil reference) to the use of bio-chemicals. However, chemicals represent an important part of the global consumption of primary energy and they cannot be substituted by other renewable sources apart from biomass (the potential use of biomass in the petrochemical industry is studied by Bos et al. $)^{34}$. Therefore, if a global substitution of fossil fuels is an aim, bio-chemicals should be included in the assessment of sustainability.

- The allocation of co-products and services is included in European regulations but there is no explicit methodology, neither for the calculation of the GHG emissions of each coproduct, nor for a medium saving of GHG emissions.

- The use of the LHV content of the co-products is mandatory in the European regulation. Nonetheless, different criteria for the allocation of products and services can be found in the literature (they are shown in Table 2, as well as their advantages and disadvantages).

- It is assumed that the final use of biofuels does not have a net impact on the global carbon balance (i.e. they are neutral). Nevertheless, the use of bio-products cannot be assumed to 
have a neutral emission of GHG. Of course, if the origin of the carbon in the bio-products is biogenic, the net emissions of $\mathrm{CO}_{2}$ are zero (neutral). However, this does not apply to the emissions of other GHGs like $\mathrm{VOC}$ and $\mathrm{NO}_{\mathrm{x}}$. The assessment of sustainability should include the final use of all co-products and services (which is of great relevance in the case of heat) ${ }^{9}$. The final use of chemicals and materials is harder to account for and estimations have to be made regarding whether there is further processing (or not) and what kind of processing there might be (production of plastics, solvents, textile, etc.). Nonetheless, combustion is not one of the final uses of chemicals and materials.

- In the case of bio-chemicals and bio-materials, there is net storage of the carbon of biogenic origin (they are not combusted) and it must be accounted for reducing the total emissions per MJ of product and year. However, European regulations do not consider it. Of course, this storage is not permanent although neither is the storage in biomass. In a first approximation, the retention of the carbon content in bio-chemicals and bio-materials could be estimated by an emission factor (\% of equivalent $\mathrm{CO}_{2}$ in the bio-chemical).

- The definition of the reference system (conventional process: using fossil fuels) is hard to carry out in thermochemical biorefineries. However, the ISO 14064 states that such a definition of the conventional process is crucial. ${ }^{35}$ For example, in the case of chemical production, some authors analyzed the GHG emissions of several bio-chemicals and compared them with the equivalent fossil process. ${ }^{36,37}$ However, it is difficult to determine the emissions of chemicals and materials as there is a multitude of fossil processes and public information is scarce.

- Indirect land-use change is under discussion and it is not yet regulated in the EU. The application in thermochemical biorefineries depends on the feedstock, and contrary to $1^{\text {st }}$ generation processes there is a wide diversity of potential feedstocks for thermochemical biorefineries (lignocellulosic biomass, agricultural and industrial residues, MSW: municipal solid waste, etc.).

- A parallel question is the cost of opportunity of the biomass and residues and the different uses that they could have (similar to indirect land-use change). For example, the use of residues is assumed to account for zero emissions according to European regulations, but it is not true that the use of residues involves neutral GHG emissions. In the case of MSW, the deposition in landfills generates methane and VOC that will be emitted into the atmosphere (in the case of efficient landfill administration, the emissions are lower and the case should be further studied). Therefore, there would be a reduction of GHG emissions. ${ }^{9}$

- In the assessment of sustainability in biorefineries, the resulting saving of GHG emissions could result in the net emissions of the process (cradle to grave) being lower than the maximum allowed in order to achieve sustainability. In this case, an extra saving is achieved. This extra saving represents an opportunity for the enhancement of the profitability of such plants if a translation into an economic parameter is possible. One 
option is to transform the extra saving of the biorefinery into extra-avoided emissions ${ }^{\dagger \dagger}$. The sale of these extra-avoided emissions would enhance the profitability of the plant. Another option is to consider the co-feeding of coal and/or natural gas to reach the limit of GHG emissions in order to achieve sustainability.

- The incorporation of BECCS (BioEnergy with Carbon Capture and Storage) to thermochemical biorefineries may be a quite interesting option for the profitability of biorefineries ${ }^{\ddagger \ddagger}$. However, the sequestered $\mathrm{CO}_{2}$, i.e. an outlet of $\mathrm{CO}_{2}$ from the atmosphere, does not necessarily imply that they are extra-avoided emissions. For example (see Figure 8 ), in a thermochemical biorefinery with BECCS, the assessment of sustainability could result in different cases (under the framework of European regulation):

A. The process before BECCS incorporation achieves a lower saving in GHG emissions than that required by the regulation. The incorporation of BECCS allows the biorefinery to just achieve the regulation. In this case, the sequestrated $\mathrm{CO}_{2}$ cannot be considered as negative emissions that could be economically valorized.

B. The process before BECCS incorporation achieves a lower saving in GHG emissions and the incorporation of BECCS allows the biorefinery to achieve a saving larger than that regulated. In this case, the sequestrated $\mathrm{CO}_{2}$ cannot be completely counted as negative emissions that could be economically valorized. Only the fraction of $\mathrm{CO}_{2}$ that is an extra saving with respect to the regulation could be valorized (extra-avoided emissions)

C. The process before BECCS incorporation achieves the same saving in GHG emissions as that required by the regulation. In this case, the sequestrated $\mathrm{CO}_{2}$ counts as negative emissions that could be economically valorized.

D. The process before BECCS incorporation achieves a larger saving in GHG emissions than that required by the regulation. In this case, there is an extra saving that does not depends on the sequestrated $\mathrm{CO}_{2}$, which again counts as negative emissions that could be economically valorized. Hence, it would be possible to sell a larger amount of $\mathrm{CO}_{2}$ credits than those from BECCS incorporation (negative emissions). If it were not possible, the whole extra-avoided emissions would not be valorized, penalizing the thermochemical biorefinery.

Table 2. Alternative for the allocation of GHG emissions in biorefineries.

\begin{tabular}{l} 
Allocation \\
\hline Mass $\mathrm{C}$ content
\end{tabular}




\begin{tabular}{|c|c|c|c|}
\hline & & of GHG emissions. & $\begin{array}{l}\text { non-containing carbon products } \\
\text { (e.g. } \mathrm{H}_{2} \text { ) and all services. }\end{array}$ \\
\hline & Total mass & $\begin{array}{l}\text { It takes all products into } \\
\text { account. }\end{array}$ & $\begin{array}{l}\text { Services are disregarded. } \\
\text { There is not a direct relation } \\
\text { between mass content and } \\
\text { energy efficiency. }\end{array}$ \\
\hline \multirow{2}{*}{ Energy } & HHV basis & $\begin{array}{l}\text { It takes into account all } \\
\text { products and services. } \\
\text { It gives a clear indication of the } \\
\text { efficiency of the process. }\end{array}$ & $\begin{array}{l}\text { It considers equivalent } \\
\text { chemicals and materials to } \\
\text { fuels. }\end{array}$ \\
\hline & LHV basis & $\begin{array}{l}\text { It takes into account all } \\
\text { products and services. } \\
\text { It is the regulated allocation in } \\
\text { the EU. }\end{array}$ & $\begin{array}{l}\text { It considers equivalent } \\
\text { chemicals and materials to } \\
\text { fuels. }\end{array}$ \\
\hline \multirow[b]{2}{*}{ Economic value } & $\begin{array}{l}\text { Present prices (of the } \\
\text { functional unit) }\end{array}$ & $\begin{array}{l}\text { It gives an accurate view of the } \\
\text { potential of GHG reduction in } \\
\text { currently demanded products } \\
\text { and services. }\end{array}$ & $\begin{array}{l}\text { It could be inaccurate for bio- } \\
\text { products whose present prices } \\
\text { are only an estimation of their } \\
\text { potential market. }\end{array}$ \\
\hline & $\begin{array}{l}\text { Future/expected prices } \\
\text { (of the functional unit) }\end{array}$ & $\begin{array}{l}\text { It shows the potential of GHG } \\
\text { reductions in estimated } \\
\text { economic scenarios, e.g. in a } \\
\text { bio-based economy with high } \\
\text { competition within } \\
\text { biorefineries. }\end{array}$ & $\begin{array}{l}\text { It is based on an estimation of } \\
\text { the future behavior of the } \\
\text { market. }\end{array}$ \\
\hline \multirow[t]{2}{*}{ [Regulations] } & $\begin{array}{l}\text { EU (energy basis: } \\
\text { LHV) }\end{array}$ & $\begin{array}{l}\text { It is the legal way in the EU for } \\
\text { the certification of biofuels. }\end{array}$ & $\begin{array}{l}\text { It does not consider the final use } \\
\text { of bio-products. } \\
\text { It is not true that the production } \\
\text { of electricity from biomass is a } \\
\text { carbon neutral activity when } \\
\text { using residues. }\end{array}$ \\
\hline & $\begin{array}{l}\text { ISO } 14044 \text { (no } \\
\text { allocation) }^{39}\end{array}$ & $\begin{array}{l}\text { It is the way for international } \\
\text { certification of bioproducts. }\end{array}$ & $\begin{array}{l}\text { It forces the selection of the final } \\
\text { use of all products and services, } \\
\text { which may be unaffordable in } \\
\text { the case of chemicals and } \\
\text { materials. }\end{array}$ \\
\hline
\end{tabular}

${ }^{\mathrm{a}}$ An analogous discussion on the allocation of GHG emissions in conventional refineries is given by Wang et al. ${ }^{40}$ 


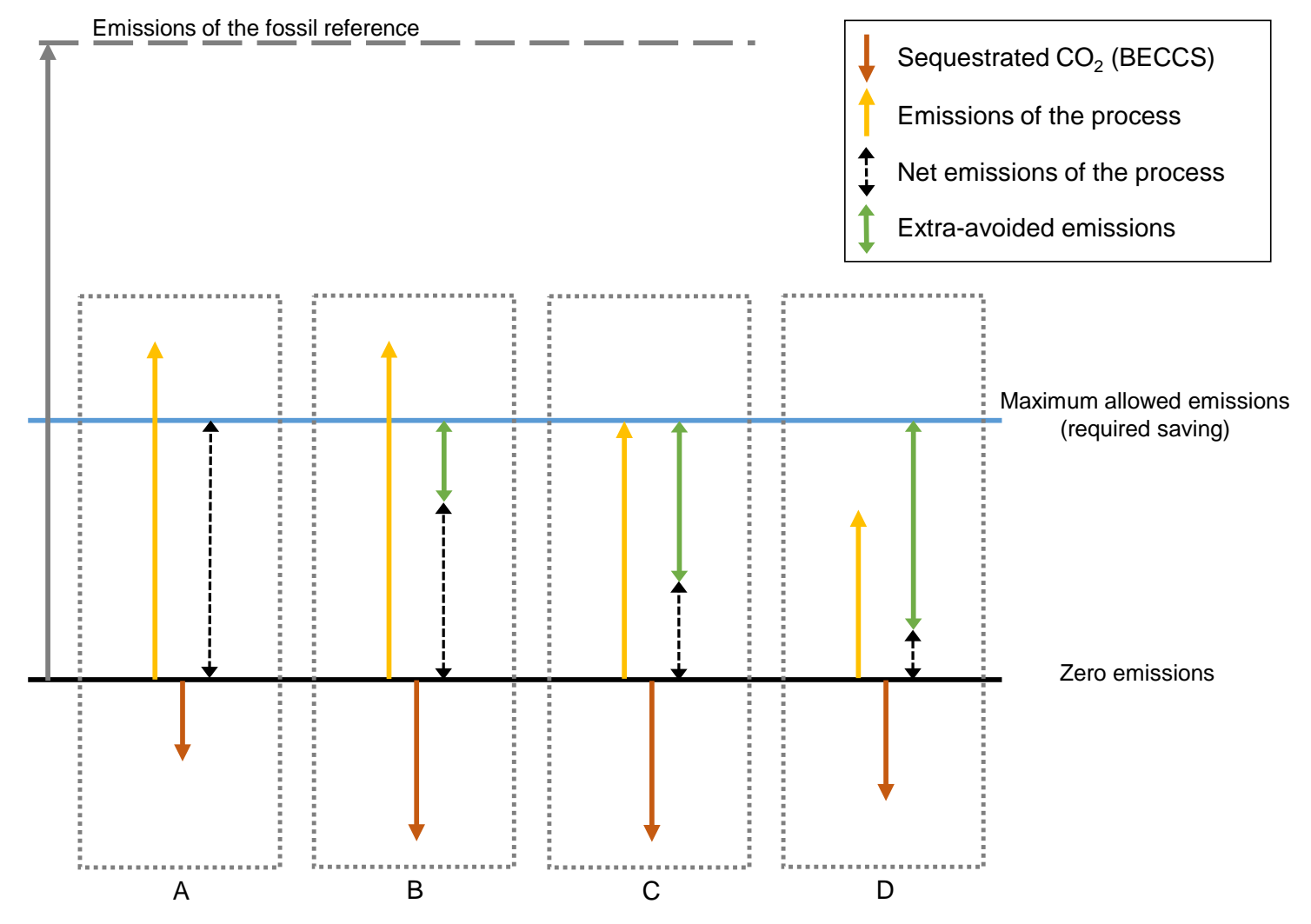

Figure 8. Different cases when BECCS is incorporated into thermochemical biorefineries.

\subsection{Process design}

The design of thermochemical biorefineries with multiproduction is a hard task. The use of general guides for thermochemical processing is helpful. ${ }^{31,41,42}$ However, regarding the peculiarities of these kind of biorefineries, the design of a thermochemical biorefinery requires of the combination of a large number of technical (gasification, cleaning, conditioning, synthesis) and economic (mix of products, regulation of the sector, investment) considerations. Some of them are common in the design of conventional BTL/G processes, but others are inherent to multiproduction and the use of a platform chemical.

In a thermochemical biorefinery with multiproduction, at least a fuel (low-value high-volume) and a chemical (high-value low-volume) should be co-produced in order to achieve maximum profitability and reduce the risk of investment. In this case, the benefits of a large-scale facility can apply to the production of low-volume products, and the income from their sale will contribute to making a plant profitable, which otherwise would produce only low-value highvolume products $^{\S \S}$. Hence, the first step is to define, according to the selected economic scenario, which fuel(s) and chemical(s) will be produced in the plant, i.e. the mix of products. According to the selected mix, a platform chemical and the corresponding chemical routes (platform-to-products) are selected. Thereafter, the gasification, cleaning and conditioning

\footnotetext{
$\S \S$ This idea is commonly misleading in the literature of biomass valorization. ${ }^{43}$
} 
technologies can be defined. For the gasifier, the typical parameters for the design/selection are the required pretreatment, the gasifying agents (e.g. $\mathrm{O}_{2}$, which would require an ASU plant), the operating pressure, and the requirements of further cleaning, the yield of light hydrocarbons and the resulting molar $\mathrm{H}_{2} / \mathrm{CO}$ ratio. For plants with multiproduction, only the $\mathrm{H}_{2} / \mathrm{CO}$ ratio requires further discussion with respect to conventional BTL/G plants. Moreover, in multiproduction plants using a platform chemical, the integration of reaction steps (material and energy) is also more complex than in BTL/G plants. Hence, a discussion on energy and material integration is appealing.

A comprehensive study of all aspects of the design of multiproduction plants is beyond the scope of this paper. Nonetheless, in order to give a fair discussion of the design of thermochemical biorefineries with multiproduction, a set of different case studies is presented using DME as the platform chemical. These case studies are simplifications limited to the main aspects that differentiate thermochemical biorefineries with multiproduction using a platform chemical.

\subsubsection{Case studies using DME as platform chemical}

The potential products using DME as the platform chemical are shown in Table 3, whose combination gives the mix of products of the biorefinery. In the case of the services, the net export/import will be determined after the design and by calculation of the material and energy balances (technical assessment). Also in Table 3, the conversion routes for the production of each co-product are shown along with their final use. The required $\mathrm{H}_{2} / \mathrm{CO}$ ratio for the synthesis of each individual product depends on how DME is synthesized from syngas.

Table 3. Potential products using DME as a platform chemical.

\begin{tabular}{|c|c|c|c|c|}
\hline Product $^{\text {a,b }}$ & Use & Route & $\mathrm{H}_{2} / \mathrm{CC}$ & tio $^{c}$ \\
\hline$D M E$ & Fuel/Chemical & - & $\begin{array}{c}1 \\
\text { (one step) }\end{array}$ & $\begin{array}{c}2 \\
\text { (two steps) }\end{array}$ \\
\hline Ethanol & Fuel/Chemical & DME hydrocarbonylation & $2 / 3$ & 2 \\
\hline Methanol & Fuel/Chemical & DME hydrocarbonylation & $5 / 4$ & - \\
\hline Methyl acetate & Chemical & DME carbonylation & $3 / 4$ & $4 / 3$ \\
\hline Acetic anhydride & Chemical & Methyl acetate carbonylation & $3 / 5$ & 1 \\
\hline Ethylene & Chemical & DME-to-olefins & 1 & 2 \\
\hline Propylene & Chemical & DME-to-olefins & 1 & 2 \\
\hline LPG & Fuel & $\begin{array}{l}\text { DME-to-olefins and DME-to- } \\
\text { gasoline }\end{array}$ & 1 & 2 \\
\hline $\begin{array}{l}\text { Synthetic } \\
\text { gasoline }\end{array}$ & Fuel & DME-to-gasoline & 1 & 2 \\
\hline Diesel & Fuel & DME-to-fuels & 1 & 2 \\
\hline Jet fuel & Fuel & DME-to-fuels & 1 & 2 \\
\hline
\end{tabular}


${ }^{a}$ Prior to the generation of DME, $\mathrm{H}_{2}$ and $\mathrm{CO}_{2}$ could be separated (conditioning of the syngas) and can join the mix of products. Furthermore, in the synthesis and conversion of $\mathrm{DME}, \mathrm{CO}_{2}$ is commonly a by-product of the reactions (incorporation of BECCS). The DME itself can be a product of the biorefinery.

${ }^{\mathrm{b}}$ The co-production of services (heat and/or electricity) is also possible, but it depends on process layout.

${ }^{c}$ The $\mathrm{H}_{2} / \mathrm{CO}$ ratio is required depending on how the DME is synthesized from syngas. ${ }^{10}$

Case study 1: material integration in a plant producing DME and ethanol

- It is important to achieve high efficiency (e.g. achieving an efficient conversion of syngas), but not to increase the complexity (related to the fixed capital investment) of the plant too much. In the DME hydrocarbonylation route, methanol is also produced along with ethanol (in a molar ratio 1:1). However, the generated methanol could be dehydrated into more DME via dehydration. ${ }^{21}$ The conversion of the methanol does not require a new reactor; it can be done in the DME synthesis reactor, ${ }^{11,12}$ so there is not an increase in equipment in the biorefinery. Therefore, the material integration of the biorefinery allows that the by-product (methanol) is completely converted in the plant producing more DME and ethanol.

Case study 2: selection of the mix of products if an EF gasifier is introduced

- If a gasifier producing a raw syngas with a low $\mathrm{H}_{2} / \mathrm{CO}$ ratio (0.5) and without tars is considered for the gasification of biomass, then DME will be more efficiently synthesized from syngas in a single reaction step (ratio of 1 ). The potential products should also be limited to those that require of a low $\mathrm{H}_{2} / \mathrm{CO}$ ratio. For example, a candidate mix of products could be DME (fuel substitute for diesel and/or natural gas), methyl acetate and acetic anhydride (high-value chemicals). The average $\mathrm{H}_{2} / \mathrm{CO}$ ratio of the mix ranges from 1 to $3 / 5$ (varying as a function of the relative volume of production of each co-product). The raw syngas from the gasifier, which does not require special conditioning (cleaning) for synthesis, must in this case, be conditioned by means of WGS $^{\star * *}$ to slightly increase its $\mathrm{H}_{2} / \mathrm{CO}$ ratio. The selection of a mix of products with higher hydrogen requirements (higher $\mathrm{H}_{2} / \mathrm{CO}$ ratio), would result in a need for larger equipment for syngas conditioning (higher investment and operating costs) and lower energy and carbon efficiency (less revenues and worse carbon conversion).

Case study 3: selection of mix of products using an i-CFB (indirectly-heated circulating fluidized bed) gasifier and a tar reformer

- If a gasifier with a high production of tar and light hydrocarbons is considered for the gasification of biomass, the removal or conversion of tars is mandatory prior to the conversion of the syngas. A tar reformer converts the tars and light hydrocarbons into more syngas, achieving a $\mathrm{H}_{2} / \mathrm{CO}$ ratio of around 1.5. The considered products are DME, ethanol (substitute for gasoline and chemical) and olefins (precursor of plastics). In this case, DME is more efficiently synthesized in a single step.

\footnotetext{
The WGS (water gas shift) reactor involves a loss of chemical energy and a loss of carbon in the plant.
} 
Case study 4: process integration

- In the integration of the process, it is of interest that the conversion of the syngas in each reaction step is carried out when it has the optimal $\mathrm{H}_{2} / \mathrm{CO}$ ratio. For example, consider a plant with an i-CFB gasifier and a tar reformer aiming to produce DME and methyl acetate (as in case study 2). The raw syngas in the biorefinery has a $\mathrm{H}_{2} / \mathrm{CO}$ ratio of 1.5, which is larger than the average required in the conversion into products (around 0.8). Hence, hydrogen can be separated, and the recovered hydrogen sold as a coproduct (low-volume). In this case, the layout brings an advantage for the recovery of hydrogen. Contrary to a plant focused on the production of hydrogen (single product), in the considered biorefinery the maximum production of hydrogen is not sought. Therefore, the production of hydrogen requires lower investment and operating costs (there is not a combination of low and high temperature WGS reactors) than in plants producing hydrogen as single product. Regarding the process flowchart (Figure 9), the fresh syngas is not used for the synthesis of DME, but for the carbonylation of DME. Examining the reaction conditions of the DME carbonylation, the reaction requires a large excess of $\mathrm{CO}$ with respect to the stoichiometry CO/DME molar ratio. The presence of hydrogen does not penalize the reaction. ${ }^{12}$ Therefore, the syngas is efficiently converted in the biorefinery.

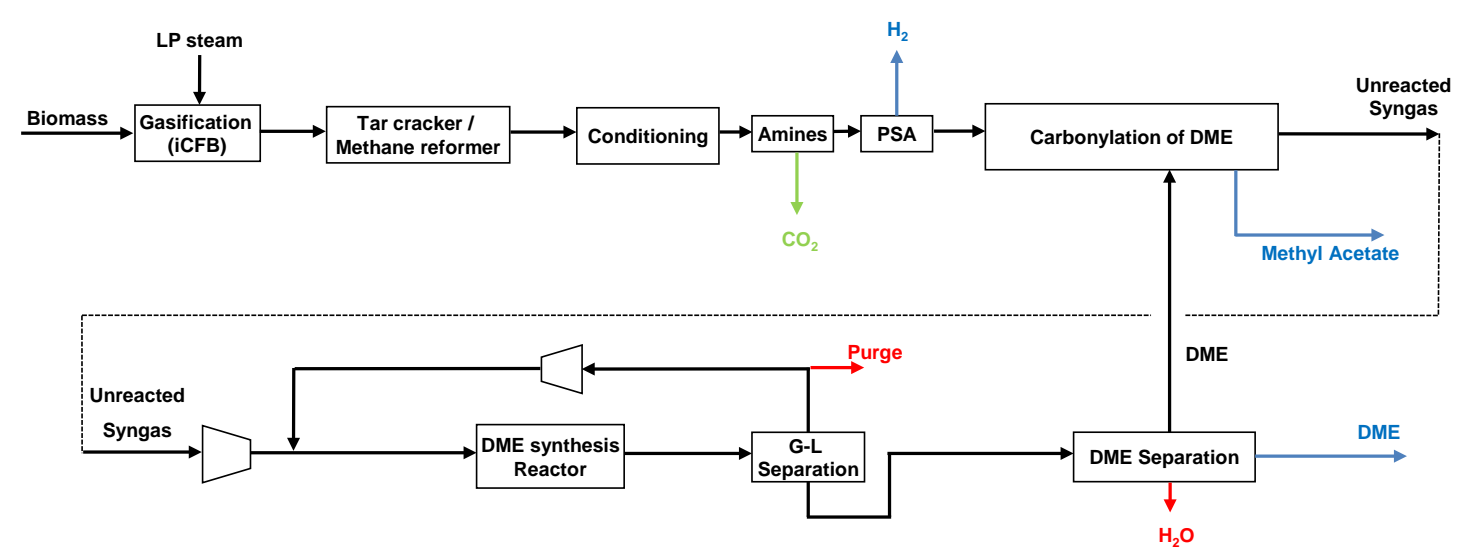

Figure 9. Process flowchart of a thermochemical biorefinery co-producing DME, methyl acetate and hydrogen (adapted from Haro et al: TR-05 concept). ${ }^{12}$ iCFB: indirect Circulating Fluidized Bed Gasifier. PSA: Pressure Swing Adsorption.

\subsection{Economic assessment}

In the economic assessment of new plants, such as thermochemical biorefineries with multiproduction, there are important uncertainties that make the resulting profitability unclear. Examples of such uncertainties are the cost of the processing technologies (gasification, syngas cleaning), the price of biomass (feedstock) and the evolution of the bio-products market (prices) and their regulation. The case of thermochemical biorefineries is somehow easier than biochemical biorefineries, since the potential bio-products are those currently used or proven 
substitutes for the fossil equivalents. Nonetheless, the profitability of thermochemical biorefineries requires, due to the larger scale of the plant, a larger investment.

For the economic assessment of thermochemical biorefineries with multiproduction, the presence of more than one main product forces an alternative to the calculation of the minimum selling price (once the internal rate of return is fixed). The problem relies on multiproduction, which gives as many variables for economic assessment as co-products the plant has. In order to address the problem, there are two options, although neither is as illustrative as the minimum selling price:

- The commercial price of co-products and services are fixed. In this case, the internal rate of return (IRR) is the result of the economic assessment.

- The IRR is fixed. In this case, the \% of change over the market prices of co-products and services is calculated (the $\%$ of change is common for all products).

An example of an economic assessment by fixing the commercial price of products is given in Haro et al., where the resulting IRR were highly satisfactory when a chemical (methyl acetate) is co-produced along with a fuel (DME). ${ }^{12}$ The calculation of the $\%$ of change was carried out in a previous publication, where the case of multiproduction (production of gasoline and ethylene) achieved profitability between the cases of single production of a fuel (gasoline) or a chemical (olefins), despite the greater complexity of the plant. ${ }^{19}$

\section{Conclusions}

The inclusion of multiproduction in thermochemical biorefineries using a platform chemical is discussed and analyzed in this paper. Multiproduction in thermochemical biorefineries allows the co-production of different sorts of products: transportation fuels, fuels for heating, chemicals (commodities and high-value products), and materials; and also services (electricity and heat). These plants benefit from the co-production of different kinds of products (low-value highvolume along with high-value low-volume), which enhance the profitability of the plant despite requiring larger and more complex plants. There is potential energy and material integration, because of the combination of routes via a platform chemical: it maximizes the conversion of the syngas and the by-products could be completely converted. The assessment of sustainability means that in the case of the co-production of chemicals, the resulting saving of GHG emissions is the largest, since they are not combusted in their final use. The incorporation of BECCS results in the achievement of negative emissions in the plant. Furthermore, if the biorefinery achieves an extra saving with respect to the regulated emissions for biorefineries, the extra-avoided emissions should also be economically valorized. 
This paper has been funded by the Spanish Ministry of Economy and Competitiveness and carried out in the framework of the project "BIOTER" (Proyecto de Investigación Fundamental No-Orientada; ENE2012-31598). The grant given by the Spanish Ministry of Education (FPU Program; AP2010-0119) to P. Haro is acknowledged.

\section{References}

[1]. IEA Bioenergy Task 42 Biorefinery. [Online] (2009). Available at: http://www.biorefinery.nl/fileadmin/biorefinery/docs/Brochure Totaal definitief HR opt.pdf [1, January 2013]

[2]. Cherubini F, Jungmeier G, Wellisch M, Willke T, Skiadas I, van Ree R et al., Toward a common classification approach for biorefinery systems. Biofuel Bioprod Bioref 3(5):534-546 (2009).

[3]. Cherubini F, The biorefinery concept: Using biomass instead of oil for producing energy and chemicals. Energy Conversion and Management 51(7):1412-21 (2010).

[4]. Biomass Energy Data Book. [Online] (2011). Available at: http://cta.ornl.gov/bedb/biorefineries/Biorefineries_Overview.shtml [1, February 2013]

[5]. Abengoa Bioenergy SA Available at: http://www.abengoabioenergy.com/web/en/nuevas_tecnologias/tecnologias/biorrefineria_integrada/ [1, February 2013]

[6]. What Is a Biorefinery? National Renewable Energy Laboratory (NREL): Biomass research. [Online] (2009). Available at: http://www.nrel.gov/biomass/biorefinery.html [1, January 2013]

[7]. Fernando S, Adhikari S, Chandrapal C, Murali N, Biorefineries: Current status, challenges, and future direction. Energy and Fuels 20(4):1727-37 (2006).

[8]. Menon V, Rao M, Trends in bioconversion of lignocellulose: Biofuels, platform chemicals \& biorefinery concept. Progress in Energy and Combustion Science 38(4):522-50 (2012).

[9]. Systems perspectives on Biorefineries 2012. Chalmers University of Technology. [Online] (2012). Available at: http://www.chalmers.se/en/areas-of-

advance/energy/cei/Pages/Systems\%20Perspectives\%20on\%20Biorefineries\%202012/Systems-Perspectives-onBiorefineries.aspx [1, January 2013]

[10]. Haro P, Ollero P, Villanueva Perales AL, Vidal-Barrero F, Potential routes for thermochemical biorefineries. Biofuel Bioprod Bioref. 7(5):551-72 (2013).

[11]. Haro P, Ollero P, Villanueva Perales AL, Reyes Valle C, Technoeconomic assessment of lignocellulosic ethanol production via DME (dimethyl ether) hydrocarbonylation. Energy 44(1):891-901 (2012).

[12]. Haro P, Ollero P, Villanueva Perales AL, Gómez-Barea A, Thermochemical biorefinery based on dimethyl ether as intermediate: Technoeconomic assessment. Appl Energy 102:950-61 (2013).

[13]. Boerrigter H, Deurwaarder EP, Bergman PCA, van Paasen SVB, van Ree R, Thermal Bio-Refinery; High-Efficient Integrated Production of Renewable Chemicals, (Transportation) Fuels, and Products from Biomass. The $2^{\text {nd }}$ World Conference and Technology Exhibition on Biomass for Energy, Industry and Climate Protection, 10-14 May 2004. Rome (2004).

[14]. Zwart IR, Thermochemical biomass based refinery process: Technological status and perspectives. Biorefinica 2006 Conference. 11-12 October 2006. Osnabrück, Germany (2006).

[15]. van Ree R, Annevelink B, Status Report Biorefinery 2007. Agrotechnology and Food Sciences Group. November 2007. Available at: http://edepot.wur.nl/42141 [1, January 2013] (2007).

[16]. Jenkins BM, Overview of Thermochemical Biorefining. Biobased Industry Outlook Conference. Iowa State University. 28-29 August 2006. Ames, lowa (2006).

[17]. Ng KS, Zhang N, Sadhukhan J, Techno-economic analysis of polygeneration systems with carbon capture and storage and CO2 reuse. Chem Eng J 219:96-108 (2013).

[18]. Zwart RWR, Boerrigter H, High efficiency co-production of synthetic natural gas (SNG) and fischer-tropsch (FT) transportation fuels from biomass. Energy and Fuels 19(2):591-7 (2005).

[19]. Haro P, Trippe F, Stahl R, Henrich E, Bio-syngas to gasoline and olefins via DME - A comprehensive technoeconomic assessment. Applied Energy 108:54-65 (2013). 
[20]. Reyes Valle C, Haro P, Villanueva Perales AL, Ollero P, Caraballo J, García Redondo JA et al., Techno-economic assessment of SNG-ethanol co-production (bio SNG-ethanol) via thermochemical conversion of biomass by indirectly heated CFB gasifier. Proceedings of the $19^{\text {th }}$ European Biomass Conference, 06-09 June 2011. Berlin, pp. 2177-80 (2011).

[21]. Tay DHS, Ng DKS, Multiple-cascade automated targeting for synthesis of a gasification-based integrated biorefinery. J Clean Prod 34:38-48 (2012).

[22]. Sadhukhan J, Ng KS, Economic and European Union environmental sustainability criteria assesment of bio-oilbased biofuel systems: Refinery integration cases. Industrial and Engineering Chemistry Research 50(11):6794808 (2011).

[23]. Fornell R, Berntsson T, Åsblad A, Techno-economic analysis of a kraft pulp-mill-based biorefinery producing both ethanol and dimethyl ether. Energy 50(1):83-92 (2013).

[24]. Hoffmann J, Rudra S, Toor SS, Holm-Nielsen JB, Rosendahl LA, Conceptual design of an integrated hydrothermal liquefaction and biogas plant for sustainable bioenergy production. Bioresour Technol 129:402-10 (2013).

[25]. Baliban RC, Elia JA, Weekman V, Floudas CA, Process synthesis of hybrid coal, biomass, and natural gas to liquids via fischer-tropsch synthesis, ZSM-5 catalytic conversion, methanol synthesis, methanol-to-gasoline, and methanol-to-olefins/distillate technologies. Computers and Chemical Engineering 47:29-56 (2012).

[26]. Baliban RC, Elia JA, Floudas CA, Biomass to liquid transportation fuels (BTL) systems: Process synthesis and global optimization framework. Energy and Environmental Science 6(1):267-87 (2013).

[27]. Meerman JC, Ramírez A, Turkenburg WC, Faaij APC, Performance of simulated flexible integrated gasification polygeneration facilities. Part A: A technical-energetic assessment. Renewable and Sustainable Energy Reviews 15(6):2563-87 (2011).

[28]. Meerman JC, Ramírez A, Turkenburg WC, Faaij APC, Performance of simulated flexible integrated gasification polygeneration facilities, part B: Economic evaluation. Renewable and Sustainable Energy Reviews 16(8):6083102 (2012).

[29]. Wang B, Gebreslassie BH, You F, Sustainable design and synthesis of hydrocarbon biorefinery via gasification pathway: Integrated life cycle assessment and technoeconomic analysis with multiobjective superstructure optimization. Computers and Chemical Engineering 52:55-76 (2013).

[30]. Hamelinck CN, Faaij APC, Future prospects for production of methanol and hydrogen from biomass. J Power Sources 111(1):1-22 (2002).

[31]. Gassner M, Maréchal F, Thermo-economic optimisation of the polygeneration of synthetic natural gas (SNG), power and heat from lignocellulosic biomass by gasification and methanation. Energy and Environmental Science 5(2):5768-89 (2012).

[32]. Larson ED, Jin H, Celik FE, Large-scale gasification-based coproduction of fuels and electricity from switchgrass. Biofuel Bioprod Bioref 3(2):174-94 (2009).

[33]. DIRECTIVE 2009/28/EC OF THE EUROPEAN PARLIAMENT AND OF THE COUNCIL of 23 April 2009 on the promotion of the use of energy from renewable sources and amending and subsequently repealing Directives 2001/77/EC and 2003/30/EC.

[34]. Bos HL, Sanders JP, Raw material demand and sourcing options for the development of a bio-based chemical industry in Europe: Part 1: Estimation of maximum demand. Biofuel Bioprod Bioref 7(3):246-59 (2013).

[35]. ISO 14064:2006. Greenhouse gases - Part 1: Specification with guidance at the organization level for quantification and reporting of greenhouse gas emissions and removals.

[36]. Hermann BG, Blok K, Patel MK, Producing bio-based bulk chemicals using industrial biotechnology saves energy and combats climate change. Environmental Science and Technology 41(22):7915-21 (2007).

[37]. Neelis ML, Patel MK, Bach PW, Haije WG, Analysis of energy use and carbon losses in the chemical and refinery industries. Report of the Utrecht University, Copernicus Institute for Sustainable Development and Innovation. Department of Science, Technology and Society (ECN-I-05-008). (2005).

[38]. Kuramochi T, Ramírez A, Turkenburg W, Faaij A, Comparative assessment of $\mathrm{CO}_{2}$ capture technologies for carbon-intensive industrial processes. Progress in Energy and Combustion Science 38(1):87-112 (2012).

[39]. ISO 14044:2006. Environmental management - Life cycle assessment - Requirements and guidelines. 
[40]. Wang M, Lee H, Molburg J, Allocation of energy use in petroleum refineries to petroleum products: Implications for life-cycle energy use and emission inventory of petroleum transportation fuels. International Journal of Life Cycle Assessment 9(1):34-44 (2004).

[41]. Kokossis AC, Yang A, Tsakalova M, Lin T-, A systems platform for the optimal synthesis of biomass based manufacturing systems. $20^{\text {th }}$ European Symposium on Computer Aided Process Engineering. 6-9 June. Ischia, Naples, Italy, pp. 1105-10 (2010).

[42]. Villanueva AL, Design of thermochemical biorefineries: Experience of Bioenergy Group of University of Seville.
FECUNDUS
Summer
School.
CIEMAT.
6
July
2012.
Madrid.
(2012).

http://grupo.us.es/bioenergia/templates/jubilee/pdf/Villanueva-Design of thermochemical biorefineries.pdf

[43]. Yun C, Kim Y, Park J, Park S, Optimal procurement and operational planning for risk management of an integrated biorefinery process. Chem Eng Res Design 87(9):1184-90 (2009). 